\title{
Influence of Rhizobium and Mycorrhizae in the Production of Seedlings of Caesalpinia Spinosa L. Taya in San Pablo, Peru
}

\section{Influencia del Rizobium y Micorrizas en la Pro- duccion de Plantones de Caesalpinia Spinosa L. Taya en San Paplo, Peru}

Memories II International

Congress Forests and

Agroforestry for the 21st

Century

Corresponding Author:

R. Zurita

vzurita2020@hotmal.com

Published: 21 January 2021

Production and Hosting by

Knowledge E

(c) R. Zurita et al. This article is distributed under the terms of the Creative Commons Attribution License, which permits unrestricted use and redistribution provided that the original author and source are credited.

\section{R. Zurita, A. Cadenillas, and M Gallardo}

Universidad Nacional de Cajamarca, Escuela de Ingeniería Forestal Cajamarca, Perú

\section{Abstract}

This research study evaluated the symbiotic influence of Mycorrhizae in the production of propagating material of Caesalpinia Spinosa L. Taya, as well as the characterization of strains of mycorrhitic fungi in field, nursery, and laboratory work. No nodules were found as a product of nitrifying bacteria in the roots of plants Caesalpinea spinosa L., and ectomycorrhitic fungi were identified in the rhizosphere, such as Basidiomicetes and species of Rhizoctonia sp and Fusarium sp. From the evaluations, T4 exceeded all treatments, such as in height, neck diameter, number of leaves, root length, and the wet and dry weight of Taya seedling. In conclusion, we say that the Caesalpinia Spinosa L. Taya, despite of belonging to the legume family, does not present nodulation; but the presence of ectomycorrhitic fungi such as the basidiomicetes in the rhizosphere and high content of organic matter, positively influences the increase in the volume of seedling in the nursery, also reflected in the absorption of protein and phosphorus.

Keywords: mycorrhizal association, seedlings, rhizobium.

\section{Resumen}

En el presente trabajo de investigación se evaluó la influencia simbiótica de micorrizas en la producción de plantones de Caesalpinea spinosa L. Taya, así como la caracterización de cepas de hongos micorríticos, realizándose el trabajo en campo, vivero, y laboratorio. No se encontró nódulos como producto de bacterias nitrificantes en las raíces de las plantas de Caesalpinea spinosa L., y se identificó hongos ectomicorríticos en la rizósfera, tales como Basidiomicetes y especies de Rhizoctonia sp y Fusarium sp. De las evaluaciones el T4, supera a todos los tratamientos como en altura, diámetro de cuello, número de hojas, longitud de raíz, peso húmedo y peso seco de plántula.Concluyendo finalmente, diremos que la Caesalpinea spinosa L. taya, a pesar de pertenecer a la familia de las Leguminosas no presenta nodulación; pero la presencia de los hongos ectomicorríticos como los basidiomicetes en la rizósfera y el alto contenido de materia orgánica, influye positivamente en el incremento del volumen de la plántula en vivero, reflejado también en la absorción de proteínas y fosforo.

Palabras Clave: asociación micorrítica, plantones, rizobium 


\section{Introducción}

La utilización de fertilizantes biológicos se ha puesto en práctica desde los años 40 en cultivos agrícolas, pero en los últimos años, ha tomado un impulso creciente en plantaciones forestales específicas. Se reconoce que la fijación biológica del nitrógeno (FBN) realiza un aporte considerable de Nitrógeno a las plantas de la familia de las Leguminosas. Actualmente, existen microorganismos como el Azospirillum sp y Micorrizas, que favorecen la adquisición de nutrientes para los cultivos, a la vez que ejercen un efecto promotor del crecimiento y tienden a superar situaciones de estrés, o simplemente ayudan al incremento de su tasa de crecimiento. La términologia micorrizas se aplica a la asociación simbiótica de las plantas con algunos hongos del suelo.

Se realizó el presente trabajo de investigación teniendo en cuenta que la Caesalpinia spinosa L. (taya), es una especie de interés económico, evaluándose a plantones de taya en interacción con microorganismos simbiontes (micorrizas y bacterias nitrificantes) en la producción y establecimiento de plantones, ya que no hay estudios reportados en cuanto a este tema, si bien sabemos que los hongos micorríticos viven en asociación simbiótica con las raíces de las plantas, estimulando la mayor ramificación del sistema radicular y disolviendo los elementos minerales insolubles del suelo, permitiendo mayor absorción de estos elementos, especialmente fósforo, recientemente se están realizando diversos estudios en relación a esta especie.

\section{Materiales y Métodos}

\subsection{Ubicación geográfica del trabajo de investigación}

El presente trabajo de investigación se realizó en tres etapas: trabajo de campo (Distrito de San Pablo), trabajo de Vivero (vivero forestal temporal de Kuntur Wasi, San Pablo) y trabajo de laboratorio, (Laboratorio de Rhizobiología y Fitopatología de la Universidad Nacional de Cajamarca).En campo se realizó la identificación de cinco zonas situados en: Kuntur Wasi; latitud sur 707'37,2”, latitud oeste $78^{\circ} 50^{\prime} 29,5^{\prime \prime}$ y altitud de 2178 m.s.n.m., Jancos; latitud sur $7^{\circ} 02^{\prime} 45^{\prime \prime}$, latitud oeste $78^{\circ} 50^{\prime} 50,7^{\prime \prime}$ y altitud de 2211,8 m.s.n.m., Rosa Pampa; latitud sur $7^{\circ} 06^{\prime} 03,8^{\prime \prime}$, latitud oeste $78^{\circ} 49^{\prime} 78,4^{\prime \prime}$ oeste y altitud 2178 m.s.n.m., Yuragalpa; latitud sur $7^{\circ} 07^{\prime} 48,5^{\prime \prime}$, latitud oeste $78^{\circ} 17^{\prime} 46.7^{\prime \prime}$ y altitud de 2800 m.s.n.m., Lanchepampa; 708'12,2" latitud sur 7845'45,9", latitud oeste y altitud de 2970,8 m.s.n.m., para la extracción de sustrato y raíces de la C. spinosa L. taya, puntos pertenecientes a la Provincia de San Pablo, Departamento de Cajamarca.

El Vivero Forestal temporal de San Pablo está ubicado en la Provincia de San Pablo, Distrito San Pablo, y Caserío Kuntur Wasi, a una altitud de 2200 m.s.n.m., longitud oeste $78^{\circ} 50$ '33,5”, y latitud sur 706’31,4”, precipitación de $680 \mathrm{~mm}$ promedio por año. De acuerdo al Servicio Nacional de Meteorología e Hidrología, 1999.

El Laboratorio de Rhizobiología, se encuentra ubicado en la Ciudad Universitaria, de la Facultad de Ciencias Agrarias de la Universidad Nacional de Cajamarca situado a una altitud de 2550 m.s.n.m., y longitud oeste 78³0', latitud Sur 7¹0’ precipitación 650 mm promedio por año, Servicio Nacional de Meteorología e Hidrología, 1999. 


\subsection{Materiales}

Los materiales experimentales son: Semilla de $C$. spinosa $L$. para la producción de plantones en el vivero forestal. Sustratos de cinco zonas identificadas, para realizar el repique de plántulas de taya, análisis de suelo, e identificación de hongos micorríticos, teniendo en cuenta las altitudes establecidas tal como aparece en la Tabla 1. Muestras de Raíces de plantas de taya de las cinco altitudes establecidas. Plantones de taya extraídos del vivero Forestal para análisis de Contenido de Proteína y Fosforo. Otros materiales; Compuestos: Glucosa, Agar, Agua destilada, Agua estéril. Reactivos: Cloruro de sodio, Bicloruro de calcio, Fosfato acido de amonio, Fosfato acido de potasio, Cloruro de fierro, Sulfato de magnesio hidratado, Malta, Thiamina. Material de vidrio: Vasos, Pipetas, Matraces, Probeta, Tubos de ensayo con tapa, Placas petri. Materiales y Herramientas en el Vivero Forestal: Arcos de fierro,Bolsas de polietileno, Sustratos, Fungicida, Repicadores, Regaderas, Mangueras, Mallas de protección, Plástico protector, Malla para sustrato, Palanas, Zapapicos, Costales, Bolsas transparentes. Equipos: Cocina eléctrica, Refrigeradora, Incubadora, Autoclave, Balanza de precisión, Mechero, Microscopio, Estufa, GPS, Cámara Fotográfica, Camioneta, Computadora, Altímetro.

\subsection{Diseño experimental}

Para evaluar la influencia de Bacterias y hongos micorríticos en la producción de plantones de C. spinosa L. instaladas en el vivero del Caserío de Kuntur Wasi, Distrito de San Pablo, Provincia de San Pablo, se aplicó el Diseño Completamente Randomizado (DCR), con seis (6) tratamientos y cuatro (4) repeticiones por tratamiento.

Unidad básica experimental: Cada unidad estuvo conformada por 320 plantones de taya, distribuidos a 1,20 m de ancho $\times 1,0 \mathrm{~m}$ de largo y $0,20 \mathrm{~m}$ de profundidad.

Variable independiente (factor de Tratamiento): Altitud de procedencia de sustratos.

\subsection{Conducción del experimento}

\subsubsection{Zonificación de las áreas de trabajo en la Provincia de San Pablo}

Se identificó con ayuda de un GPS, diferentes zonas altitudinales comprendidas entre los 2000 y 3000 m.s.n.m., para la ubicación de las áreas de muestreo, se tuvo en cuenta la existencia de plantas naturales de taya adultas, en estado de floración y buen estado sanitario (Tabla 1).

\subsubsection{Selección de plantas individuales de Taya para recolección de muestras de nódulos y hongos micorrízicos}

De cada zona seleccionada, se tomó muestras de raíces de plantas de taya para la identificación de nódulos nitrificantes y hongos micorríticos, donde se seleccionó y escogió tres plantas, en buen estado de sanidad y en plena floración. 


\subsubsection{Recolección de sustrato para vivero y análisis e identificación de Microorganismos}

La recolección de los sustratos, para la inoculación de plántulas en vivero de las diferentes zonas seleccionadas, se tomó en cuenta que el sustrato presente características del manto fúngico (blanquecino), y que este dentro de la proyección del diámetro de la copa de la planta seleccionada.

Una vez seleccionada la zona de muestreo, se extrajo el sustrato previamente tamizado.

Finalmente se trasladó los sustratos al vivero temporal, para utilizarlo como material de repique en plántulas de $C$. spinosa L. (taya), que estuvieron en el almacigo aptas para el repique.

La recolección de sustratos, para análisis de suelo y para la identificación de las micorrizas, se tomó del mismo sustrato que se utilizó para el repique de las plántulas de taya, así como también se tomó una muestra del sustrato testigo, sustrato que fue trabajado en el mismo vivero. Finalmente se trasladó al laboratorio, un kilogramo de cada uno de los sustratos extraídos incluyendo al testigo.

\subsubsection{Recolección de Nódulos}

Para realizar la recolección de nódulos, se usó el criterio propuesto por el Manual de métodos de evaluación selección y manejo Agronómico [1]. Para la recolección de nódulos se removió el suelo, alrededor de la planta de taya, a fin de extraer las raíces primarias y secundarias, para la identificación de los nódulos.

\subsubsection{Obtención de sustrato para identificación de micorrizas}

De las zonas ya establecidas se tomó una muestra de sustrato de la parte superficial del suelo, y del sustrato que se encontró en contacto con las raíces de taya, se tamizó el sustrato con una malla de un centímetro por un centímetro. Finalmente se trasladó al laboratorio de Rhizobiología para la identificación de los hongos micorríticos.

\subsubsection{Trabajo en vivero}

1. Llenado de bolsas para repique

Sé trabajó el llenado de bolsas con sustrato preparado en vivero; tierra agrícola, arena y materia orgánica, en una proporción (1:1:1) distribuidas en las camas de repique.

2. Distribución de tratamientos

Para la distribución de tratamientos y el testigo en estudio, se realizó la distribución de tratamientos según el diseño completamente randomizado (DCR), en el vivero de San Pablo-Kuntur Wasi, de la Provincia de San Pablo, con cuatro repeticiones (Tabla 2). 
3. Repique de plántulas de Taya

Las plántulas de taya fueron extraídas de las camas de almacigo, posteriormente repicadas en las bolsas preparadas con el sustrato de vivero de Kuntur Wasi. Se aperturó un hoyo con ayuda de un repicador manual a las bolsas que contenían el sustrato preparado en vivero, para las plántulas de taya, luego se inoculó las plántulas con los sustratos extraídos de las cinco diferentes zonas y el testigo en estudio, colocando el sustrato en los hoyos de repique conteniendo las plántulas de taya.

4. Labores culturales

Se realizó riegos en forma oportuna, deshierbo y remoción de plántulas.

\subsubsection{Trabajo en laboratorio}

1. Identificación de nódulos

Se trabajó con las raíces seleccionadas y extraídas de las plantas de taya adultas, para su posterior identificación, ya que reúnen las características para la identificación de presencia de nódulos en las raíces.

2. Identificación de micorrizas

Se preparó el medio de cultivo, Melin Norkrans Modificado (Mnn) + harina de trigo, luego se esterilizó del medio, y luego se transfirió a placas petric, finalmente se incubó a $30^{\circ} \mathrm{C}$ por espacio de $24 \mathrm{hr}$, para comprobar su esterilidad del medio, quedando lista para la transferencia del inóculo.

3. Preparación del inóculo de acuerdo al protocolo CIAT

4. Proceso para caracterización de hongos micorríticos

Una vez purificada la cepa, se extrajo una pequeña muestra y se la colocó en una lámina porta objeto, y se agregó una gota de medio de cultivo líquido de papa dextrosa y agar (PDA) para el desarrollo del hongo, se acondicionó un medio húmedo dentro de una placa petri con agua destilada estéril, sobre un soporte que evita el contacto directo del agua con la muestra de la lámina.

Se procedió a identificar las muestras después de 05 a 07 días, cuatro días aproximadamente, hasta que el hongo desarrolle sus estructuras completamente.

5. Clareo y Tinción de las raíces para detectar presencia de formaciones micorríticas Para realizar este trabajo se siguió la técnica recomendada por Kormank [2]

\subsection{Evaluaciones registradas}

\subsubsection{En campo}

Se evaluó la presencia de nódulos en las raíces de C. spinosa L. de las plantas adultas seleccionadas de las zonas de extracción de sustrato. 


\subsubsection{En vivero}

Se evaluó mensualmente al azar 10 plántulas por tratamiento; altura de plántula (AP), diámetro de cuello de plántulas en vivero (DCP), número de hojas (NH) y longitud de raíz (LR).

\subsubsection{En laboratorio}

1. Peso húmedo de las plántulas en gramos (PHP)

Se realizó en una balanza analítica pesando las 10 plántulas en evaluación, tomando la parte aérea y la parte radicular de la plántula.

2. Peso seco de las plántulas en gramos (PSP)

Se realizó después de pesar las plántulas en PHP, colocándolos en la estufa a $105^{\circ} \mathrm{C}$ durante $24 \mathrm{hr}$, para posteriormente ser pesadas y determinar el PSP correspondiente por tratamiento.

3. Análisis de suelo

Para realizar el análisis del suelo se tomó las muestras de sustrato de cada una de las zonas de estudio y el testigo, dicho análisis se realizó en el laboratorio del Instituto de Innovación Agraria (INIA) donde se determinó $\mathrm{P}$ en ppm, $\mathrm{K}$ en ppm, $\mathrm{PH}$, M.O\%, Arena\%, limo\% y Arcilla\% y determinar la clase textural de cada sustrato.

4. Análisis de proteína y fosforo en plántulas de Taya

Las muestras para el análisis de proteína y fósforo se determinaron en base de plántula seca en el laboratorio del INIA evaluando así: Porcentaje del contenido de proteína y porcentaje del contenido de fósforo.

5. Conteo de crecimiento de hongos micorrízicos

Para el conteo de colonias de microorganismos de las muestras de suelo, presentes en medio de cultivo Mmn, se realizó una división de cuatro partes iguales por cada placa petri, contabilizándose en forma individual para luego obtener el total de colonias por placa, con características de hongos micorríticos.

6. Caracterización de cepas de hongos micorrízicos

Una vez purificadas las cepas de los hongos, con características micorríticas, se procedió a su respectiva identificación en el laboratorio de Fitopatología.

\section{Resultados y Discusión}

3.1. Caracterización de microorganismos simbióticos (hongos micorríticos, Rhizobium sp) aislados de la Rizosfera del cultivo de Taya 


\subsubsection{A nivel de campo}

No se encontró nodulación efectuados por bacterias nitrificantes en las raíces de las plantas de Taya, coincidiendo con estudios realizados por Dion [3].

\subsubsection{A nivel de laboratorio}

Se determinó que con el tratamiento 4 (T4) existe mayor número de colonias, con caracteristicas micorríticas (8) por placa, esto se debe a que en este suelo, que procede de Yuragalpa cituado a una altura de 2800 m.s.n.m. tiene mayor porcentaje en contenido de materia orgánica 23,32\% (Tabla 3) coincidiendo con Kruckelmann (1975), donde indica que la mejor respuesta al incremento de las micorrizas, es debida probablemente al aporte en el contenido de materia orgánica que permite mejorar la estructura del suelo, favorece la aireación y la retención de agua. El uso de las micorrizas, es una alternativa económica con calidad ambiental que permite reducir el tiempo de permanencia de plántulas de frutales y forestales en la etapa de vivero.

Sin embargo las colonias por bacterias y otros organismos fueron menores (44) debido posiblemente a la presencia de hongos que inhiben su desarrollo tal como lo menciona Esquivel [4] indica que las micorrizas tienen mecanismos indirectos ayudan a evitar que las plantas se enfermen por la producción antibióticos, y el escaso número de colonias se obtuvo del testigo T6 (Tabla 3).

\section{Table 1}

Claves de tratamientos y ubicación de zonas de extracción de muestras de sustratos y raíces.

\begin{tabular}{lllll|l}
$\begin{array}{l}\text { Tratamientos } \\
\begin{array}{l}\text { Clave de } \\
\text { tratamientos }\end{array}\end{array}$ & Procedencia & Altitud m.s.n.m. & Latitud sur & Longitud oeste \\
\hline $\mathbf{T}_{1}$ & Kuntur Wasi & 2178 & $7^{\circ} 07^{\prime} 37.2^{\prime \prime}$ & $78^{\circ} 50^{\prime} 29.5^{\prime \prime}$ \\
\hline $\mathbf{T}_{2}$ & Jancos & 2211.8 & $7^{\circ} 02^{\prime} 45^{\prime \prime}$ & $78^{\circ} 50^{\prime} 50.7^{\prime \prime}$ \\
$\mathbf{T}_{3}$ & Rosa Pampa & 2566 & $7^{\circ} 06^{\prime} 03.8^{\prime \prime}$ & $7^{\circ} 49^{\prime} 78.4^{\prime \prime}$ \\
$\mathbf{T}_{4}$ & Yuragalpa & 2800 & $7^{\circ} 07^{\prime} 48.5^{\prime \prime}$ & $78^{\circ} 17^{\prime} 46.7^{\prime \prime}$ \\
$\mathbf{T}_{5}$ & Lanchepampa & 2970.8 & $7^{\circ} 08^{\prime} 12.2^{\prime \prime}$ & $78^{\circ} 45^{\prime} 45.9^{\prime \prime}$ \\
$\mathbf{T}_{6}$ & $\begin{array}{l}\text { Testigo sustrato } \\
\text { de vivero }\end{array}$ & 2100 & $7^{\circ} 07^{\prime} 30.2^{\prime \prime}$ & $78^{\circ} 49^{\prime} 37.2^{\prime \prime}$ \\
\hline
\end{tabular}

\section{Table 2}

Croquis de distribución de los tratamientos en vivero de Kuntur Wasi.

\begin{tabular}{l|l|l|l|l|l|l} 
Repetición & \multicolumn{7}{c}{ Tratamientos } \\
I & $\mathbf{T}_{2}$ & $\mathbf{T}_{5}$ & $\mathbf{T}_{1}$ & $\mathbf{T}_{3}$ & $\mathbf{T}_{4}$ & $\mathbf{T}_{6}$ \\
II & $\mathbf{T}_{3}$ & $\mathbf{T}_{2}$ & $\mathbf{T}_{5}$ & $\mathbf{T}_{1}$ & $\mathbf{T}_{6}$ & $\mathbf{T}_{4}$ \\
III & $\mathbf{T}_{6}$ & $\mathbf{T}_{1}$ & $\mathbf{T}_{4}$ & $\mathbf{T}_{2}$ & $\mathbf{T}_{5}$ & $\mathbf{T}_{3}$ \\
IV & $\mathbf{T}_{1}$ & $\mathbf{T}_{6}$ & $\mathbf{T}_{2}$ & $\mathbf{T}_{4}$ & $\mathbf{T}_{3}$ & $\mathbf{T}_{5}$
\end{tabular}


Table 3

Determinación de número de colonias de microorganismos.

\begin{tabular}{l|l|l} 
Tratamiento & $\begin{array}{l}\text { Colonias de hongos con } \\
\text { características micorríticos }\end{array}$ & $\begin{array}{l}\text { Bacterias } \mathbf{y} \text { otros } \\
\text { microorganismos }\end{array}$ \\
\hline $\mathbf{T}_{1}$ & 3 & 80 \\
$\mathbf{T}_{2}$ & 5 & 71 \\
$\mathbf{T}_{3}$ & 4 & 79 \\
$\mathbf{T}_{4}$ & 8 & 44 \\
$\mathbf{T}_{5}$ & 3 & 87 \\
$\mathbf{T}_{6}$ & 2 & 102 \\
\hline
\end{tabular}

\begin{tabular}{|c|c|c|c|c|c|c|c|c|c|c|c|}
\hline Lugar & \multicolumn{2}{|c|}{ Kuntur Wasi } & \multicolumn{2}{|c|}{ Jancos } & \multicolumn{2}{|c|}{ Rosapampa } & \multicolumn{2}{|c|}{ Yuragalpa } & \multicolumn{2}{|c|}{ Lamchepampa } & $\mathrm{S}^{\circ}$ de vivero \\
\hline Clave & $\mathrm{T} 1$ & $\mathrm{~T} 1$ & $\mathrm{~T} 2$ & $\mathrm{~T} 2$ & T3 & $\mathrm{T}_{3}$ & $\mathrm{~T} 4$ & $\mathrm{~T} 4$ & T5 & $\mathrm{T} 5$ & $\mathrm{~T} 6$ \\
\hline \multicolumn{12}{|l|}{ Fotografía } \\
\hline $\begin{array}{l}\text { hongos } \\
\text { encontrados }\end{array}$ & \multicolumn{2}{|c|}{ Basidiomicetes } & \multicolumn{2}{|c|}{ Basidiomicetes } & \multicolumn{2}{|c|}{ Basidiomicetes } & \multicolumn{2}{|c|}{$\begin{array}{l}\text { Basidiomicetes } \\
\text { Rhizoctonia sp } \\
\text { Fusarium sp }\end{array}$} & \multicolumn{2}{|c|}{ Basidiomicetes } & $\begin{array}{l}\text { No } \quad \text { se } \\
\text { encontró } \\
\text { H.M. }\end{array}$ \\
\hline
\end{tabular}

Figure 1

Caracterización de cepas de hongos micorríticos.

Table 4

Efecto de las micorrizas en altura de planta $(A P)$, número de hojas (NH) y longitud de raíz (LR).

\begin{tabular}{|c|c|c|c|c|}
\hline \multirow[t]{2}{*}{ Clave } & \multirow{2}{*}{$\begin{array}{l}\text { Altura en } \\
\text { m.s.n.m. }\end{array}$} & \multicolumn{3}{|c|}{ Factor de crecimiento } \\
\hline & & (AP) (NS) $\mathrm{Cm}$ & (NH) (NS) u & (LG) (NS) Cm \\
\hline $\mathbf{T}_{1}$ & 2178 & 42,250 & 10,2500 & 35,750 \\
\hline $\mathbf{T}_{2}$ & 2211,8 & 42,250 & 10,2000 & 36,000 \\
\hline $\mathbf{T}_{3}$ & 2566 & 38,125 & 10,0000 & 34,500 \\
\hline $\mathbf{T}_{4}$ & 2800 & 43,250 & 10,5000 & 37,525 \\
\hline $\mathbf{T}_{5}$ & 2970,8 & 40,336 & 10,2500 & 37,000 \\
\hline $\mathbf{T}_{6}$ & Testigo & 39,750 & 9,5000 & 35,000 \\
\hline c.v. & & 11,17348 & 8,896211 & 7,663983 \\
\hline
\end{tabular}

\subsubsection{Caracterización de cepas de hongos micorríticos}

Se caracterizó a los hongos de acuerdo a su estructura y cuerpo fructífero, los tratamientos; T1, T2, T3, T4 y T5, se identificaron hongos con características de Basidiomicetes, que pertenecen al grupo de las ectomicorrízas, presentando en su estructura miceliar hifas septadas, presencia de la fíbula o clamp, y dichas estructuras no presentaron cuerpos fructíferos, estudios realizados por Sánchez [5].Con respecto al T6 no se encontró hongos micorríticos (Figura 1). 
Table 5

Diámetro de cuello de plántulas (DP).

\begin{tabular}{|c|c|c|c|c|c|}
\hline FV & GL & $\begin{array}{l}\text { Suma de } \\
\text { cuadrados }\end{array}$ & $\begin{array}{l}\text { Cuadrado de la } \\
\text { media }\end{array}$ & F-Valor & $\operatorname{Pr}>\mathrm{F}$ \\
\hline REP & 3 & 0,00124583 & 0,00041528 & 0,43 & 0,7354 \\
\hline Trat & 5 & 0,05732083 & 0,01146417 & $11,84^{* *}$ & $<0,0001$ \\
\hline Error & 15 & 0,01452917 & 0,00096861 & & \\
\hline \multirow[t]{3}{*}{ Total } & 23 & 0,07309583 & & & \\
\hline & & & $\mathrm{CV}$ & & \\
\hline & & & 5,043487 & & \\
\hline
\end{tabular}

Table 6

Análisis de variancia para el diámetro de cuello de plántula en vivero.

Clave/Tratamiento
$\mathbf{T}_{4}$
$\mathbf{T}_{2}$
$\mathbf{T}_{1}$
$\mathbf{T}_{3}$
$\mathbf{T}_{6}$
$\mathbf{T}_{5}$

$\begin{array}{ll}\text { Media/mm } & \text { Duncan } \\ 0,66250 & \text { A } \\ 0,64250 & \text { A } \\ 0,64250 & \text { A } \\ 0,62250 & \text { A } \\ 0,62000 & \text { A } \\ 0,51250 & \text { B }\end{array}$

Table 7

Análisis de variancia para de peso seco y húmedo de plántulas de taya.

\begin{tabular}{l|l|l|l} 
Clave & Altura m.s.n.m. & \multicolumn{2}{c}{ Factor de peso } \\
\hline $\mathbf{T}_{1}$ & 2178 & (PHP g.) (NS) & (PSP g.) (NS) \\
\hline $\mathbf{T}_{2}$ & 2211,8 & 14,8500 & 5,1750 \\
$\mathbf{T}_{3}$ & 2566 & 14,2000 & 5,2125 \\
$\mathbf{T}_{4}$ & 2800 & 13,8750 & 4,9500 \\
$\mathbf{T}_{5}$ & 2970,8 & 15,1975 & 5,3250 \\
$\mathbf{T}_{6}$ & Testigo & 14,1750 & 5,0000 \\
$\mathbf{C . V}$ & & 14,3500 & 5,0750 \\
\hline
\end{tabular}

\subsection{Determinación de la influencia simbiótica de los hongos micor- ríticos en la producción de platones de Taya}

Los resultados obtenidos en las diferentes evaluaciones a nivel de vivero se aplicaron el procedimiento ANOVA. 


\section{Table 8}

Análisis de proteina y fosforo de las plántulas de taya

Tratamientos
$\mathbf{T}_{1}$
$\mathbf{T}_{2}$
$\mathbf{T}_{3}$
$\mathbf{T}_{4}$
$\mathbf{T}_{5}$
$\mathbf{T}_{6}$

\begin{tabular}{|l|l|}
\hline Proteína \% & Fósforo \% \\
\hline 6,65 & 0,31 \\
\hline 7,00 & 0,33 \\
\hline 7,77 & 0,33 \\
\hline 8,58 & 0,34 \\
\hline 8,00 & 0,30 \\
\hline 7,35 & 0,33 \\
\hline
\end{tabular}

\subsubsection{Efecto de las micorrizas en altura de planta (AP), número de hojas (NH) y longitud de raíz (LR)}

Se presenta el análisis de variancia combinado para altura de planta (AP), número de hojas $(\mathrm{NH})$ y longitud de raíz $(\mathrm{LR})$, donde podemos observar que con el tratamiento 4 (T4), numéricamente se obtuvo la mayor (AP), (NH) y (LG), debido a la influencia de materia orgánica (M.O.) en el suelo $(23,32 \%)$ y a los hongos micorríticos, quienes proporcionan mayor explanación de las raíces para la absorción de nutrientes y agua a las plántulas, la M.O., capta mayor humedad, factor que influyen en el crecimiento de las plantas, trabajos similares se obtuvieron por Muthukumar y Udaiyan [6] quienes encontraron resultados positivos en cuanto al crecimiento y producción de plantas de Vigna sp, inoculadas con micorriza, como respuesta a la aplicación de materia orgánica, influyendo en la altura de la planta, número de hojas, y longitud de raíz, debido que por efecto de los hongos micorríticos hay mayor área de exploración por las raíces, por ende mayor absorción de nutrientes y agua (Tabla 4).

\subsubsection{Análisis de variancia para el diámetro de cuello de planta (DCP)}

Se presenta la prueba de comparación de medias para el DCP de taya, lo cual nos indica que los tratamientos; T4, T2, T1, T3, T6, son estadísticamente iguales y superior al tratamiento 5 (T5), debido posiblemente a que en este tratamiento el $\mathrm{pH}$ es de 7,5 y existe mayor número de bacterias, la presencia de microorganismos antagónicos en el suelo tales como, Verticillium sp, Penicillium sp, Fusarium sp, puede influir negativamente en la supervivencia de la planta hospedera (Tabla 5).

Numéricamente con el tratamiento 4 (T4) se obtiene mayor diámetro de cuello de plántulas de taya, debido a la acción del sustrato conteniendo mayor materia orgánica (23,32\%), y al mayor número de cepas de hongos micorríticos (8), los que influyen en el incremento del diámetro de las plántulas, trabajos similares se obtuvieron por Davel y Ortega [7] quienes afirman que en la importancia de las variables relacionadas con la retención nutrientes y de agua en el suelo durante el período de crecimiento de Pino radiata, lo cual es importante los niveles altos de materia orgánica del suelo. Estas capas orgánicas son altas en humedad, ricas en nutrientes y representan excelentes substratos para la formación de micorrizas (Tabla 6). 


\subsubsection{Peso húmedo (PHP) y seco de plántulas de Taya (PSP)}

Se presenta el análisis de variancia combinado para PHP y PSP, extraídas del vivero de Kuntur Wasi, donde se aprecia que todos los tratamientos estadísticamente son iguales, pero numéricamente con el tratamiento 4 (T4), se obtuvo el mayor PHP $(15,20$ g) y PSP (5,32 g), debido a la influencia del contenido de M.O. (Tabla 7), y mayor número de colonias de hongos micorríticos (Tabla 6), los cuales absorben mayor cantidad de agua y nutrientes minerales para las plántulas, reflejados en los Gráficos 6 y 7, trabajos similares se obtuvieron por Muthukumar y Udaiyan [6] que encontraron resultados positivos en el crecimiento y producción de las plantas, inoculadas con micorriza, como respuesta a la aplicación de M.O. influyendo en la absorción de nutrientes y agua, afirmando que la vaina micótica que se forma alrededor de las raíces proporciona mayor superficie de absorción de los compuestos minerales que la de la raíz sola, lo que favorece al incremento de peso de la planta.

\subsubsection{Análisis del contenido de proteína y fósforo en plántulas de taya extraídas del vivero}

El tratamiento 4 (T4) se obtuvo el mayor contenido de proteína (8,58\%) y fósforo $(0,34 \%)$ superando al testigo que contiene $7,35 \%$ y $0,3 \%$, respectivamente, este incremento de proteina y fósforo con respecto a los demás tratamienotos incluyendo el testigo, se debe a la acción benéfica de los hongos micorríticos, y el alto contenido de la matertia orgánica en el suelo y debido a que los hongos proporcionan especificamente fósforo, agua y otros nutrientes que influyen en el contenido de proteina y fósforo de las plantulas de Caesalpines spinosa L. taya, trabajos similares se obtubieron por EE INTA [8] donde afirma que las plantas con micorrizas absorben y acumulan más fosforo que las plantas sin micorrizar. Puesto que el fosforo es un nutriente de baja movilidad en el suelo y la raíz debe llegar a él para absorberlo (Tabla 8).

\section{Conclusiones}

No se encontró nódulos como producto de bacterias nitrificantes en las raíces de las plantas de C. spinosa L. Taya.

Se identificó hongos ectomicorríticos en la rizósfera, tales como Basidiomicetes y especies de Rhizoctonia, no se encontró hongos endomicorríticos en las raíces de $C$. spinosa L. Taya.

La asociación simbiótica de los hongos micorríticos y contenido de materia orgánica influyeron positivamente en el incremento de volumen en la producción de plantones de C. spinosa L. Taya, superando el tratamiento 4 numéricamente al resto de tratamientos, incluso al testigo (T6). 


\section{References}

[1] CIAT (Centro de Investigación Agrícola Tropical). Manual de Métodos de Evaluación Selección y manejo Agronómico [Manual of Evaluation Methods Selection and Agronomic Management]. Colombia: Centro Internacional de Agricultura Tropical Apartado. 1988. p 102. Spanish

[2] Kormank (1980).

[3] Dion (2008).

[4] Esquivel R. 2008. La otra cara de la microbiología. Microorganismos que alimentan, protegen a las plantas, Edt. Hispano Americana, de Mexico, D.F. Vol IV, 250 p.

[5] Sánchez P. Endomicorrizas y agroecosistemas [Endomycorrhizae and agroecosystems]. En: Seminario internacional de Manejo sostenible de la Producción Agropecuaria. Popayan: Universidad Nacional de Palmira; 1997. p 49-71. Spanish

[6] Muthukumar y Udaiyan (2002).

[7] Davel M, Ortega A. Estimación del índice de sitio para pino oregón a partir de variables ambientales en la Patagonia Andina [Estimation of the site index for oregon pine from environmental variables in Andean Patagonia,En línea]. Argentina: Bosque Valdivia, v. 24, n. 1. 2003 [Accedido en 02 mayo 2010]. Disponible en <http://www.scielo.cl/scielo.php?script=sci_arttext\&pid= S0717-92002003000100005\&lng=es\&nrm=iso>. doi: 10.4067/S0717-92002003000100005. Spanish

[8] EE INTA Estación Experimental Agropecuaria Marcos Juares. Las micorrizas en trigo y su relación con la absorción de fósforo del suelo [Mycorrhizae in wheat and their relationship with the absorption of phosphorus from the soil,En Línea]. Agentina. 2008 [Consultado 06 de Abr 2010]. Formato $\mathrm{ASCCl}$. Disponible en http://www.inta.gov.ar/MJUAREZ/info/documentos/Suelos/trigomicorrizas08. pdf. Spanish

[9] AEET. (Asociación Española de Ecología Terrestre). Interacciones entre las comunidades de hongos de micorrizas arbuscular y de plantas [Interactions between arbuscular and plant mycorrhizal fungal communities,En línea] España. 2009 [Consultado el 8 de Dic. 2009]. Disponible en http://www. revistaecosistemas.net/pdfs/606.pdf. Spanish

[10] ANICOLSA DEL PERU S.A.C. La taya y condiciones de reforestación en el Alto Jequetepeque, Microcuenca de San Juan - Cajamarca [The sizing and reforestation conditions in Alto Jequetepeque, Micro-basin of San Juan - Cajamarca,En linea]. Peru: v. 10 n. 2 Lima. 2007 [Consultado el 15 Feb 2010]. Formato ASCCL. Disponible en http://revistas.concytec.gob.pe/scielo.php?script=sciarttext\&pid= S1810-99932007000200007\&lng=es\&nrm=iso

[11] Araujo P. Proyecto de desarrollo integral la libertad - Cajamarca [Comprehensive development project of liberty - Cajamarca]. F1 Peru-Lima. Boca Ratón: CRC Press. Boca Ratón. 1996. p 155-186. Spanish

[12] Azcón A, Barea J. Endomycorhizal fungi and Rhizobium as Biological Fertilizars in Medicago sativa. 1985. p 279-325, 327.

[13] Azcón C, Barea M. Micorrizas investigación y ciencia [Mycorrhiza research and science]. Barcelona, España. 1980; 47: 8-16. Spanish

[14] Bonfante \& Perotto. Las asociaciones micorriza-arbúsculo (AM) son el tipo más común, que ocurre en $\sim 80$ especies de plantas [Mycorrhiza-arbuscule (AM) associations are the most common type, occurring in $~ 80$ plant species]. Colombia: Universidad Nacional de Colombia. 1995. p 3-76. Spanish

[15] Burbano H. Los Microorganismos del Suelo, una visión sobre sus componentes bioorganicos [Soil Microorganisms, an overview of its bioorganic components]. Universidad de Nariño: Pasto. 1989. p 141-145. Spanish

[16] CIAT (Centro de Investigación Agrícola Tropical). 2009. Rhizobiología [Rhizobiology,En línea]. Bolivia. 2006 [Consultado el 11 de Ene 2010]. Formato ASCCI. Disponible en http://www.ciatbo.org/productos/ rhizobiologia.php. Spanish

[17] CORPOICA Corporación Colombiana de Investigación Agropecuaria. Efecto de las micorrizas y el sustrato [Effect of mycorrhizae and the substrate,En línea]. Colombia. 2005 [Consultado el $20 \mathrm{Abr}$ 2010]. Formato ASCCl. Disponible en http://www.corpoica.org.co/SitioWeb/Archivos/oferta/ EfectoDeLasMicorrizasYEISustrato.pdf. Spanish

[18] Díaz M. Endogene Spores Numbers in Soli and Vesicular - Arbuscular Mycorrhiza in Wheat as Influenced by Season and Soli Treatments. Trans. Br. Mycol.soc. 1998;54:53-63.

[19] El cuaderno del porque biotecnología. Aspectos generales de las micorrizas [General aspects of mycorrhizae.,En línea]. España: Formato Microsoft Word - Versión en HTML. 2009 [consultado el 10 de Ene 2010]. Disponible en http://www.forestaluchile.cl/curso/fivegf/mico.htm. Spanish

[20] Escobar C, Colorado G, Paez D. Micorriza Vesicula Arbuscular [Mycorrhiza Vesicula Arbuscular]. Bogota: Editorial Produmedios. 1998. p 200. Spanish

[21] Garcia T. Las Micorrizas [Mycorrhizae,En línea]. Ecuador. 2009 [Consultado el 20 Ene 2010]. Formato ASCCI. Disponible en http://agrodominicano.blogspot.com/2009/04/las-micorrizas.html. Spanish 
[22] Gerdemenn W. Vesicular - Arbuscular Mycorrhiza and Plan Growth. Ann.Rev. Phytopathol. 1975;6: 397-418.

[23] Gianinazzi S. Endomycorrhization control le en agriculture, en horticulture et an arboricultures. problems et progress [Endomycorrhization controls in agriculture, horticulture and arboriculture. problems and progress]. En: les Mycorrhizes biologie et Utilization. Ed. INRA. 1982. p 231-240. French

[24] Infojardin. Articulo todo micorrizas [Article of all mycorrhizae,En línea]. Brazil. 2007 [Consultado el 16 de Ene 2010].Formato ASCCI. Disponible en http://www.infojardin.com/foro/showthread.php?t=37321. Spanish

[25] Huyman S. Micorrhizae and production of Crops. Nature. Trans. Br. Mycol. Soc. 1980; 287: 487-488.

[26] Jardines. Las micorrizas hongos beneficiosos [Beneficial fungal mycorrhizae,En línea]. España: Murillo. 2009 [Consultado el 13 de Ene 2010]. Formato ASCCI. Disponible el http://www.plantasyhogar.com/ jardin/jardines/?pagina=jardinjardines_013_013. Spanish

[27] MIOD. Universo invisible bajo nuestros pies, los suelos y la vida, las micorrizas cableando el suelo [Invisible universe under our feet, soils and life, mycorrhizae wiring the soil,En línea]. España. 2006 [Consultado el 10 de Ene 2010]. Formato ASPX. Disponible en http://weblogs.madrimasd.org/universo/ archive/2006/07/04/33555.aspx. Spanish

[28] Salisburry F, Ross C. Fisiología vegetal [Plant physiology]. México: Editorial Iberoamericana. 1994. p 151- 153

[29] Sylvia A, Ponce L, Carassa R, Reyes W. Efecto de la aplicación de efluentes orgánicos de tambo sobre la producción de verdeos y propiedades físico-químicas del suelo [Effect of the application of organic effluents from dairy farms on the production of greens and physical-chemical properties of the soil,En Línea]. Uruguay: Facultad de Agronomía. Notas. Técnicas № 16. 1992 [Consultado 02 May 2010]. p 16. Formato PDF. Disponible en http://www.fagro.edu.uy/〜edafologia/curso/Material\{\%\}20de\{\%\}2Olectura/ Materia\{\%\}20Organica/organica.pdf. Spanish

[30] Thomas J. Microbial formation of secondary and tertiary amines in municipal sewage. September 1981; 42: 461-463.

[31] Ungicol. Micorrizol - Presentación, hongos formadores de micorrizas [Mycorrhizol - Presentation, mycorrhizal forming fungi,En línea]. Colombia. 2008 [Consultado el 14 de Ene 2010]. Formato ASPX. Disponible en http://www.fungicol.com/web/micorrizas.html. Spanish

[32] UNNE Universidad Nacional del Nor Este. Micorrizas en la agricultura [Mycorrhizae in agriculture,En línea]. Argentina. 2002 [Consultado el 19 de Oct 2009 [. Formato ASCCl. Disponible en ovilloshttp: //www.biologia.edu.ar/fungi/micorrizas.htm. Spanish

[33] Kengal Bonsai. Micorrizas [Mycorrhizae,En línea]. Venezuela. 2007 [Consultado el 19 de Oct 2009]. Formato ASCCI. Disponible en Http//www.kengalbonsai.com/indec.tht?page11. Spanish

[34] Kruckelmann, W. Effect of fertilizers, Soli, Tillageand plant species on Frenquency of endogone Chlammydospores and mycorrhizal infection in Arable soils. En: endomycorrhizas. Sanders FE, Mosse B, Tinker PB (eds). 1975. p 511-525.

[35] Manual Silvo Agropecuario. Producción y uso de suelos y aguas [Production and use of soil and water]. Cajamarca- Perú: Tomo VII SESA-UNC. 1984. Spanish

[36] Odum E. Ecología. El puente entre la ciencia y la sociedad [The bridge between science and society]. Primera Edición. México: Editorial MC Graw Hill; 1998. p 199-204. Spanish

[37] ONER.Recursos Naturales del Perú, aprovechamiento integral y racional de la taya Caesalpinia spinosa caesalpinia tinctoria [Natural Resources of Peru, comprehensive and rational use of the Taya Caesalpinia spinosa - caesalpinia tinctoria]. Revista. 1980. p 21-35. Spanish

[38] Salas E, Blanco A. Selección de plantas hospederas y efecto del fosforo para la producción del inóculo de hongos formadores de micorrizas [Selection of host plants and effect of phosphorus for the production of the inoculum of mycorrhizal fungi]. Costa Rica; 2000. p 11-17. Spanish

[39] Trappe L. Mycorrhizal reactions to pesticides. Ann. Rev. Phytopathol. 1984;22: 331-395.

[40] Vásquez A. Experimentación agrícola. Diseños estadísticos para la investigación científica y tecnológica [Agricultural experimentation. Statistical designs for scientific and technological research]. Lima - Perú: Edi. Amaru editores s.a. 1ra edi. 1990. p 274. Spanish

[41] William L. 1986. Suelos Forestales, Edi [Forest Soils]. México: Limusa. 1986. p 239-255. Spanish 